\title{
Prune-Belly Sendromlu Bir Olguda Erken Prenatal Girişim ile Başarılı Tedavi
}

SUCCESSFUL TREATMENT BY EARLY PRENATAL INTERVENTION: IN A CASE WITH PRUNEBELLY SYNDROME

\author{
Aydın ERDEMİR ${ }^{1}$, Sefa KELEKÇİ ${ }^{2}$, Ebru TÜRKOĞLU ${ }^{1}$, Hese COŞAR ${ }^{1}$, Zelal KAHRAMANER ${ }^{1}$, \\ Sümer SÜTÇÜOĞLU ${ }^{1}$, Çağdaş ÇÖLLÜOĞLU ${ }^{2}$, Sefa KURT ${ }^{2}$, Esra ARUN ÖZER ${ }^{1}$
}

1 İzmir Tepecik Eğitim Ve Araştırma Hastanesi, Neonatoloji Kliniği

2ízmir Ege Doğum Evi Kadın Hastalıkları Eğitim Araştırma Hastanesi, Perinatoloji Kliniği

\begin{abstract}
Öz
Prune-Belly Sendromu (PBS) abdominal kasların hipoplazisi, üriner system anomalileri ve bilateral inmemiş testis ile karakterize konjenital bir hastalıktır. Üriner sistem tutulumu \%60 mortaliteye sahip olan son dönem böbrek hastalığı ve pulmoner hipoplazi komplikasyonları ile en önemli prognostik faktördür. PBS'nin kalıtım şekli bilinmemesine rağmen, hastalığın bir genetik temeli olduğu düşünülmektedir. Antenatal dönemde üriner sistemdeki obstrüksiyonun giderilmesi hastaların yaşam şansını arttırmaktadır. Biz prenatal dönemde vezikoamniyotik şant uygulanan ve böylece az etkilenen ailesel bir PBS olgusu sunduk.

Anahtar sözcükler: Abdominal kas hipoplazisi, Eagle Barrett Sendromu, Prune-Belly Sendromu, üriner sistem obstrüksiyonu, vezikoamniyotik şant

ABSTRACT

Prune-Belly Syndrome (PBS) is a congenital disorder characterized by abdominal wall musculature deficiency, urinary tract anomalies and bilateral cryptorchidism. Urinary tract disease is the most important prognostic factor with the complications of pulmonary hypoplasia and end stage renal disease resulting in a mortality rate of $60 \%$. Although the mode of inheritance of PBS is unclear, it has been hypothesized that PBS has a genetic basis. In the antenatal period relieving urinary tract obstruction can improve the survival rate of patients with PBS. We report a neonate with familial prune-belly syndrome who was applied vesico-amniotic shunt and so was affected slightly.

Keywords: Deficiency of abdominal musculature, Eagle Barrett syndrome, Prune-Belly syndrome, urinary tract obstruction, vesico-amniotic shunt
\end{abstract}

\author{
Aydın ERDEMiR \\ İzmir Tepecik Eğitim \\ Ve Araştırma Hastanesi \\ Neonatoloji Kliniği \\ Yenişehir, İZMIR
}

Prune-Belly Sendromu (PBS) etyolojisi bilinmeyen ve daha çok erkeklerde görülen nadir bir konjenital hastalıktır. Bu anomali Eagle Barrett sendromu ve abdominal kas eksikliği sendromu olarak da bilinmektedir. PBS in- sidansı 30.000-50.000 canlı doğumda 1'dir. Hastalığın X'e bağlı resesif geçiş gösterdiği düşünülmesine rağmen, kalıtım şekli tam olarak bilinmemektedir. Karakteristik triadı abdominal kas eksikliği veya yokluğu, bilateral 
inmemiş testis ve renal displazi, megaüreter, megasistis, üretral obstrüksiyon gibi üriner sistem anomalileridir. Mesaneden idrarın uzaklaştırılmasındaki yetersizlik oligohidramnios, pulmoner hipoplazi ve Potter Sendromuna neden olmaktadir. Sendrom etkilenen anatomik bölgenin yerine ve şiddetine göre geniş bir spektruma sahiptir. Alt üriner bölgedeki obstrüksiyonu gidermek, idrar akımını sağlamak ve renal hasarı önlemek için erken cerrahi müdahale gerekmektedir $(1,2)$.

Burada, intrauterin dönemde idrar akımını sağlamak üzere vezikoamniyotik şant uygulanarak diğer dört erkek kardeşinde rastlanan ağır bulguların gelişmesi önlenen bir PBS olgusu sunulmuştur.

\section{OLGU SUNUMU}

36 yaşında G6P5 olan gebe kadın prenatal tanı merkezimize başvurdu. Antenatal 15. gestasyonel haftada yapilan ilk ultrasonografi incelemesinde megasistis ve hafif oligohidramnios saptand. Biyometri son adet tarihi ile uyumlu bulundu. Amniyosentez yapılıp, karyotip gönderildikten sonra gebeliğin 19. haftasında vezikoamniyotik şant takıldı. Fetal idrar analizi ve karyotip analizi normal saptandı. Vezikoamniyotik şant gebeliğin 28. haftasına kadar iyi çalıştı. Gebeliğin 30. gestasyonel haftasında ikinci kez vezikoamniyotik şant takıldı.

Gebeliğin 37. gestasyonel haftasında sezeryan ile erkek bebek doğurtuldu. Hasta doğumdan hemen sonra solunum sıkıntısı nedeniyle yenidoğan yoğun bakım servisine alındı. Anne baba arasında birinci derece akrabalık mevcuttu. Hastanın soygeçmişinden 4 erkek kardeşinin PBS tanısı aldığı, bunlardan birinin infant döneminde kaybedildiği, diğer üçünün kronik böbrek yetmezliği nedeniyle diyaliz programında olduğu ve 1 kız kardeşinin tamamen sağlıklı olduğu öğrenildi. Hastanın vücut ağırlığı 2650 gr (10-50 persentil), boyu $44 \mathrm{~cm}$ (50 persentil) ve baş çevresi $34 \mathrm{~cm}$ (50-90 persentil) saptandı. Diğer fizik muayenesinde hafif solunum sıkıntısı ve bilateral inmemiş testis saptandı (Resim 1). Solunum sıkıntısı mekanik ventilasyonda nazal sürekli pozitif havayolu basıncı desteği ile
24 saat içinde tamamen düzeldi. İdrar çıkışı yeterli ve böbrek fonksiyon testleri normal olduğundan intrauterin dönemde takılmış olan şant kateteri çıkarıldı. Yapılan abdominal ve pelvik ultrasonografi sonucunda bilateral inmemiş testis (inguinal kanalda), normalden ince abdominal kaslar ve belirgin olarak genişlemiş mesane saptandı. Voiding sistoüretrografi çalışmasında reflünün olmadığı ancak mesanede yüksek miktarda rezidü idrar kaldığı görüldü (Resim 2). Ekokardiyografi, tüm vücut kemik grafileri, kraniyal ve kalça ultrasonografisi normal saptandı. Ek anomali saptanmadı. Hasta postnatal 12. gün profilaktik oral amoksisilin tedavisi ile taburcu edildi.

\section{TARTIŞMA}

Prune-Belly sendromu ilk kez Parker tarafından 1895 yılında tanımlanmıştır (3). Abdominal duvar kaslarında eksiklik, üriner sistem anomalileri ve bilateral inmemiş testis triadı ile karakterize nadir görülen bir sendromdur (4). İnsidansı 30.000-50.000 canlı doğumda 1 olarak rapor edilmektedir ve olguların \%95'ini erkekler oluşturmaktadır (5). Kalıtım şekli tam olarak bilinmemektedir ancak bildirilen ailesel PBS olgularının çoğunluğunu erkekler oluşturmaktadır. Bu nedenle en iyi X'e bağlı kalıtım şekli ile açılanabilmektedir (6). Bizim olgumuzun da 4 erkek kardeşi PBS iken, 1 kız kardeşi sağlıklı idi. Weber ve ark'nın sunduğu ailesel PBS'li bir olguda 1q41-44 lokusunda mutasyon gösterilmiştir (7). Olgumuzun prenatal dönemde yapılan kromozom analizi normal olmasına karŞın, bu mutasyon çalışılmamıştır.

Prune-Belly sendromunun etyolojisi tam olarak bilinmemektedir, ancak 2 teori ile açıklanmaya çalışılmaktadır: Mezenkimal bozukluk teorisi, üretral obstrüksiyon teorisi. İlk teoride anomalilerin abdominal duvar ve genitoüriner sistemin geliştiği lateral mezodermdeki erken bir hasar ile ilişkili olduğu savunulmaktadır (2). İkinci teoride ise gestasyonun erken döneminde distal üretral obstrüksiyonun mesane ve üreterlerde aşırı dilatasyona neden olduğu, bu dilatasyonun abdominal kas gelişimi, prostat gelişimi ve testislerin skrotuma inişi için fiziksel bir bariyer oluşturduğu ileri sürülmektedir (8). 

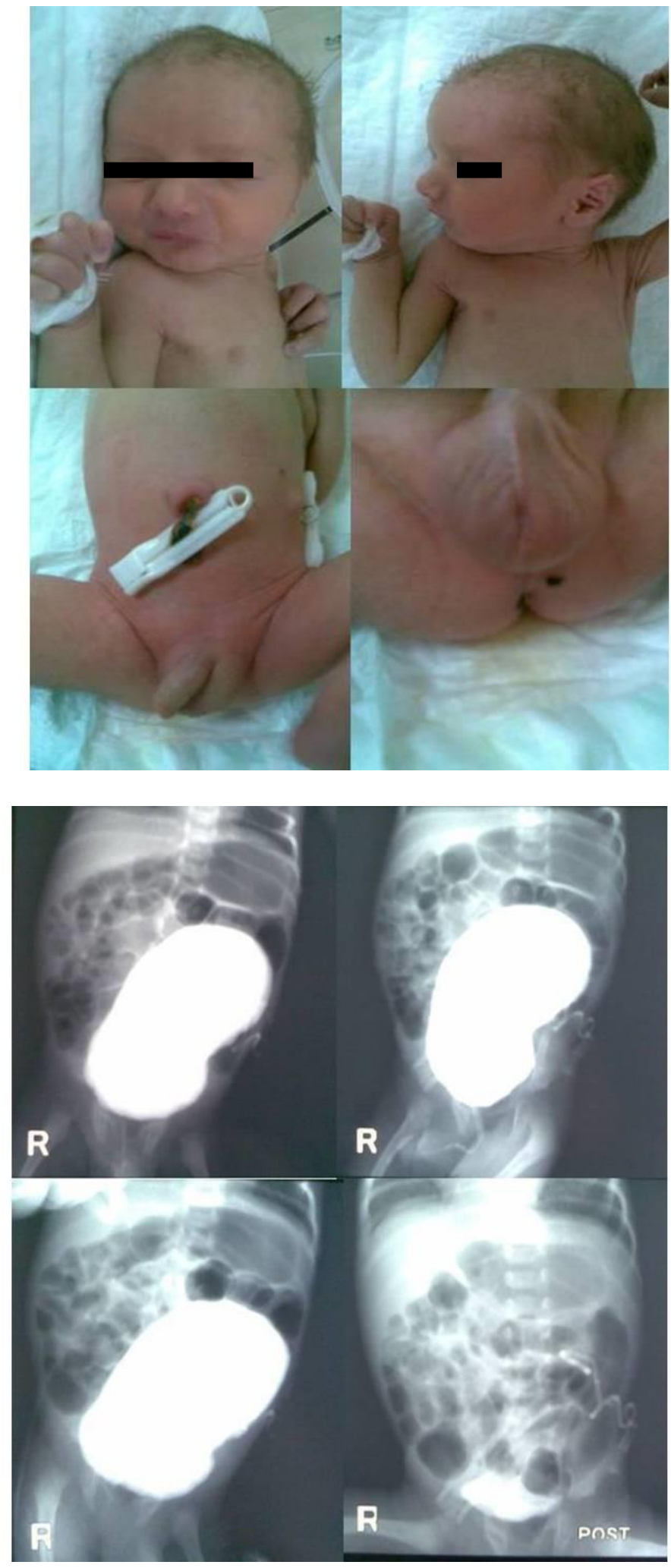

Resim 1. Olgumuzun görünümü

Resim 2. Voiding sistoüretrografide genişlemiş mesane görünümü 
İdrar üretimi veya ekskresyonundaki yetersizlik, abdominal duvar kompresyonu sonucunda karakteristik yüz görünümü ve ekstremite kontraksiyonu gibi fetal anomaliler ile sonuçlanan oligohidramniosa yol açmaktadır. Yeterli miktarda amniyotik sıvı normal akciğer gelişimi için gereklidir. Öte yandan, genişlemiş mesanenin abdominal duvarın gelişmekte olan myotomları üzerine oluşturduğu basınç, abdominal duvar anomalilerine yol açabilmektedir (9). Antenatal dönemde tedavi edilmeyen PBS olgularında üriner obstrüksiyonun derecesine bağlı olarak pulmoner hipoplazi ve abdominal duvar defektleri oluşmaktadır (10). Üriner obstrüksiyonlu olgularda intrauterin şant uygulamasının şant uygulanmayanlarla karşılaştırıldığında yaşam şansını artırıp artırmadığı tartışmalı olmasına karşın, intrauterin şant yerleştirilmesi mesane distansiyonunu önlemektedir, böylece renal fonksiyonları korumaktadır (11). Bu olguların çoğunda kabul edilebilir renal ve mesane fonksiyonları olmaktadır. Bizim olgumuzda da genişlemiş mesane dışında üriner sistem anomalisi ve pulmoner hipoplazi olmaması ve karın duvarının normal görünümde olması erken dönemde takılan vezikoamniyotik şantın koruyucu olduğunu düşündürmektedir.

Prune-Belly sendromu olan olgularda intrauterin cerrahi müdahale için gerekli kriterler oligohidramnios, megasistis, ilerlemiş hidronefroz, normal karyotip, üriner indeksin iyi olması (idrar sodyumu $<100 \mathrm{mg} / \mathrm{dL}$ ve idrar ozmolalitesi $<210 \mathrm{mOsm}$ ) ve olgunun 2 . veya 3 . trimesterde olmasıdır (10). Bizim olgumuzda şant yerleştirilmeden önce bakılan fetal idrar analizi ve karyotip analizi normal saptand1.

Prune-Belly sendromunun en karakteristik bulgusu abdominal iskelet kaslarının her 3 tabakasını içeren bozukluğa bağlı olarak abdominal derinin gevşek ve buruşuk olmasıdır. Bu bozukluk intestinal peristaltizmin görülmesine ve intraabdominal-retroperitoneal organların kolayca palpasyonuna izin vermektedir (2). Abdominal derinin bu karakteristik görünümü aşırı üriner asiti olan ağır olgularda daha belirgindir. Bizim olgumuzda kas dokusunun normalden daha ince olduğu ultrasonografik olarak görülmesine karşın, diğer 4 erkek kardeşinin aksine deri görünümü normale yakın idi. Diğer dört kardeşin deri görünümü karakteristik olarak gevşek olup, bir ta- nesinin tekrarlayan düzeltici cerrahi operasyonlar geçirdiği öğrenildi

Prune-Belly sendromunun klasik triadına ek olarak kalp, akciğer, iskelet ve gastrointestinal sistem gibi ek organ anomalileri \%75 oranında rapor edilmiştir (10). Bizim olgumuzda ve kardeşlerinde herhangi bir ek anomaliye rastlanmadi.

Prune-Belly sendromunun tekrarlama riski bilinmemektedir ancak sonraki gebeliklerde bu riskin oldukça düşük olduğu düşünülmektedir. Bu olgu aynı ailede 5 erkek kardeşin de PBS hastası olması ve diğer erkek kardeşlerine göre çok hafif etkilenmesi nedeniyle sunuldu. Erken dönemde uygun intrauterin müdahale ile olgumuzda olduğu gibi hastalığın çok daha hafif seyredebileceği vurgulanmak istenmiştir.

\section{KAYNAKLAR}

1. Diao B, Diallo Y, Fall PA, et al. Prune Belly syndrome. Epidemiologic, clinic and therapeutic aspects. Prog Urol 2008;18:470-474.

2. Sutherland RS, Mevorach RA, Kogan BA. The prunebelly syndrome: current insights. Paediatr Nephrol 1995;9:770-778.

3. Parker R. Absence of abdominal muscles in an infant. Trans Clin Soc 1895;28:201-203.

4. Wheatley JM, Stephens FD, Hutson JM. Prune-belly syndrome: ongoing controversies regarding pathogenesis and management. Semin Pediatr Surg 1996;5:95-106.

5. Herman TE, Siegel MJ. Prune belly syndrome. J Perinatol 2009;29:69-71.

6. Ramasamy R, Haviland M, Woodard JR, Barone JG. Patterns of inheritance in familial prune belly syndrome. Urology 2005;65:1227.

7. Weber S, Mir S, Schlingmann KP, et al. Gene locus ambiguity in posterior urethral valves/prune-belly syndrome. Pediatr Nephrol 2005;20:1036-1042.

8. Reinberg Y, Manivel JC, PettinatoG, Gonzalez R. Development of renal failure in children with the prune belly syndrome. J Urol 1991;145:1017-1019.

9. Greskovich FJ, Nyberg LM. The prune belly syndrome: a review of its etiology, defects, treatment and prognosis. J Urol 1988;140:707-712.

10. Perez-Brayfield MR, Gatti J, Berkman S, et al. In utero 
intervention in a patient with prune-belly syndrome and severe urethral hypoplasia. Urology 2001;57:1178.

11. McLorie G, Farhat W, Khoury A, Geary D, Ryan G. Out- come analysis of vesicoamniotic shunting in a comprehensive population. J Urol 2001;166:1036-1040. 